\title{
59 EFFECT OF HIGH INTENSITY INTERVAL TRAINING AND SLOW, CONTINUOUS TRAINING ON VO,MAX OF SCHOOL GOING NON-ATHLETE MALES: A COMPARATIVE STUDY
}

Vivekanand Upadhyay, ${ }^{1}$ Abhishek Chowdhery, ${ }^{2}$ Manabendra Bhattacharyya ${ }^{2}{ }^{1}$ Sports Medicine Centre, BEG, Roorkee, Uttaranchal, India; ${ }^{2}$ Department of Sports Medicine, National Institute of Sports, Patiala, Punjab, India

10.1136/bjsm.2010.078725.59

Most endurance athletes use high intensity training (HIT) methods to train for competitions. The effects of low to moderate intensity training on aerobic fitness are well documented. The relative impact of short, HIT versus slow, long distance training has been debated for decades. This study seeks to compare the effect of $\mathrm{VO}_{2} \mathrm{max}$, a measure of endurance capacity, on school-going males. Twenty-two school-going nonathlete males between 14 and 17 years of age with no history of systemic illness were randomly divided into HIT group $(n=12)$ and slow continuous training (SCT) group $(n=10)$. The HIT group was imparted thrice weekly training of six bouts of 2-min high-intensity run alternated with 2-min rest while SCT group was made to run five times every week for $60 \mathrm{~min}$ of slow continuous run $\left(75 \%\right.$ of $\mathrm{HR}_{\max }$ for age). Both groups were trained for 6 weeks. Pre- and post-training $\mathrm{VO}_{2} \max$ were recorded for each group by bleep test. Pre-training mean $\mathrm{VO}_{2} \max$ was $40.3 \mathrm{ml} / \mathrm{kg} / \mathrm{min}$. Subsequent to training, HIT group showed mean improvement in $\mathrm{VO}_{2}$ max by $4.5 \mathrm{ml} / \mathrm{kg} /$ min $(11.7 \%)$ while SCT group showed mean improvement in $\mathrm{VO}_{2} \mathrm{max}$ by $2.2 \mathrm{ml} / \mathrm{kg} / \mathrm{min}(6.0 \%)$. High intensity interval training is an effective endurance training tool in non-athletic school going male population and provides better improvement in $\mathrm{VO}_{2}$ max than SCT. 